the development of multiple sclerosis, or indirectly and more likely, by immunological response to such virus infected cells. It is well known that chromosomally integrated, endogenous or exogenous retroviruses can be induced to replicate by immunological mechanisms.

Evidence for the existence of a human endogenous retrovirus is slowly, but steadily accumulating. Retrovirus-like particles can regularly be observed budding from human placental trophoblasts (see ref.2 for review). Morphologically indistinguishable viruses have been detected in all investigated trophoblastcontaining human teratocarcinoma cell lines. Animal retrovirus core (gag-) related antigens and corresponding antibodies have repeatedly been found in healthy individuals and in patients with autoimmune disorders (most recently in ref.4). Furthermore, naturally occurring antibodies to endogenous retroviruses are widespread in animals, including higher primates ${ }^{5}$.

Like exogenous retroviruses, induced endogenous strains insert their envelope glycoproteins into the host's cell membrane, rendering the cell vulnerable to immunological attack ${ }^{6}$. In astrocytes or other glial cells, this process may lead to immunological exposure of myelin basic protein (MBP) or other antigens, sensitizing and activating MBP-specific $\mathrm{T}$ cells. Thus, induction of endogenous retroviruses, either directly by horizontally transmissible viruses like measles, varicella or influenza or indirectly by the immune response to such virus infected cells, may turn out to explain anti-retroviral antibodies in multiple sclerosis patients.

REINHARD KURTH

Paul-Ehrlich-Institut,

Paul-Ehrlich-Str. 42-44,

6000 Frankfurt am Main 70, FRG

1. Koprowski, H. et al. Nature 318, 154-160 (1985). 2. Löwer. R. et al. J. gen. Virol. 65, 887-898 (1984)

3. Boller, K et al J gen. Virol 64, 2549-2559 (1983)

4. Rucheton, M. et al. Virology 144, 468-480 (1985).

5. Fine, D.L. \& Arthur, L.O. Virology 112, 49-6I (1981)

Kurth. R. et al. Nature 279, 197-201 (1979).

\section{Archaebacterial status quo is defended}

Sir-In the interest of the young progressive field of molecular phylogeny the debate between Lake and the "orthodoxy of archaebacteria" should be reduced to its factual basis. Lake et al. claim (1) that the urkingdom of the archaebacteria ${ }^{1-3}$ be divided into two distinct urkingdoms the "eocytes", comprising the genus Sulfolobus and the Thermoproteales and the "archaebacteria", comprising the rest"; and (2) that the Halobacteriaceae (or, rather, Halobacteriales) be transferred from the urkingdom of the archaebacteria into that of the eubacteria which they, after its expansion, re-christened "photocytes"s.

- Lake bases his claims on a comparison
SCIENTIFCCORRESPONDENCE

of details of the three-dimensional structure of ribosomes as revealed by electron microscopy. The phylogenetic usefulness of this feature, at the present level of resolution, has been profoundly queried by Stöffler-Meilicke et al. and Stöffler and Stöffler-Meilicke ${ }^{7}$

- The division of the archaebacteria into two branches, methanogens plus halophiles and sulphur-dependent archaebacteria, had been recognized previous$1 y^{8,9}$. Yet the sequences of $16 \mathrm{~S}$ rRNAs ${ }^{10,11}$ and many other feature designs of both branches are clearly too similar to justify their promotion to kingdom level ${ }^{10}$.

- The alleged homology of the purple membrane of some halobacteria and the photosynthetic machinery of several groups of eubacteria, the only argument besides ribosome shape quoted in support of the creation of the "photocyte" kingdom, is at best an analogy in principle (light energy utilization). Homology (or identity of origin) must be proven before it can prove relatedness.

Lake et al. discount the features supporting the "orthodox" view of one kingdom of the archaebacteria including the halophiles mainly in two ways:

- So-called plesiomorphic properties (shared by "archaebacteria", "eocytes" and Halobacteriaceae but not eubacteria) are considered useless for cladistics in contrast to the "synapomorphic properties" which have served to establish the proposed tree. The reason for this astonishing conversion of good archaebacterial features ("orthodox" meaning) into "shared" plesiomorphic properties is simply the proposed division of one phylum into three. Are there other "synapomorphic" features common to halobacteria and eubacteria? And, if the archaebacterial properties are plesiomorphic, why are they not shared by any eubacteria? Such terms should only be assigned after analysis and not used in a dialectical and tendentious way.

- As Lederer explains below, the proposals of Lake et al. in contrast to the tree derived from rRNA sequences comparison, prove invalid when tested by the consistency criteria of Felsenstein ${ }^{12}$. The kingdom of the archaebacteria remains a solid entity in our incomplete understanding of the early phase of biotic evolution.

WOLFRAM ZILLIG

Max-Planck-Institut für Biochemie,

8033 Martinsried bei München, FRG

\footnotetext{
Woese, C.R. \& Fox, G.E. Proc. natn. Acad. Sci. U.S.A. 74, 5088-5090 (1977)

Woese C R Magrim, J.\& Fox, G.E. J. molec. Evol 11, 245-252 (1978)

Fox, G.E. et al. Science 209, 457-463 (1980)

4. Lake, J.A., Henderson, E., Oakes, M. \& Clark M.W. Proc, natn. Acad. Sci. U.S. A. 81, 3786-3790 (1984) Lake, J.A. et al. Proc. natn. Acad. Sci. U.S.A. 82, 37163720 (1985)

Stöffler-Meilicke, M. Böhme, C Strobel, O., Böck, A. \& Stöffler, G. Science (in the press)

Stöffler, G. \& Stöffler-Meilicke, M. System. appl. MicroStöfler, G. \& Stöf
biol. (in the press).

. Zillig, W., Schnabel, R., Tu, J. \& Stetter, K.O. Naturwissenschaften 69, 197-204 (1982)
}

Woese, C.R., Gupta, R., Hahn, C.M., Zillig, W. \& Tu, J. System. appl. microbiol. 5, 97-105 (1984)

10. Woese, C.R. \& Olsen, G.J. System. appl. Microbiol. (in the press).

1. Hummel, H., Jarsch, M. \& Böck, A. Microbiology (in the press).

12. Felsenstein, J. System. Zool. 27, 401-410 (1978)

SIR-In his letter "An alternative to archaebacterial dogma" (Nature 319, 626; 1986), Lake claims that the archaebacterial tree proposed by Woese and Olsen (System. appl. Microbiol. in the press) is inconsistent because of unequal clockrates in different branches of the tree, citing the work of Felsenstein (Syst. Zool. 27,$401 ; 1978$ ).

According to Felsenstein, in an unrooted tree with four branches the relevant sums of transition probabilities, which determine the branching of the tree, are not affected by the exact placement of the root and thus different clockrates.

By alternatively omitting one branch of the two trees shown in Lake's letter, five trees with four branches are obtained in both cases. Taking the branch lengths to represent the transition probabilities, one can calculate Felsenstein's probability sums $\left(P_{100}+P_{0011}, P_{1010}+P_{0101}+P_{1001}+P_{0110}\right)$. All five trees with four branches deduced from the tree of Woese did not violate the consistency condition $\left(P_{1100}+P_{0011}\right.$ must be largest), whereas the five trees deduced from the tree of Lake violated the consistency condition in four out of five cases. In the one consistent case (a tree with eukaryotes omitted), the phylogenetic distance between methanogens and halobacteria used in Lake's tree was 30\% greater than that found in Woese's tree.

Using Felsenstein's criteria it therefore seems inappropriate to depart from the "archaebacterial dogma".

Hermann Lederer

Max-Planck-Institut für Biochemie, 8033 Martinsried bei München, FRG

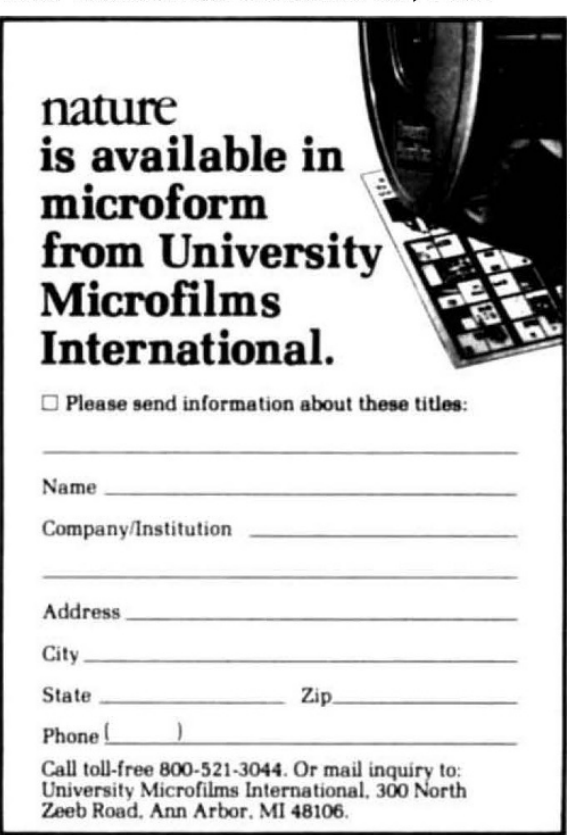

